\title{
Conception and Improvement of the Legal Regulation of Technical
}

\section{Investigation in China}

\section{Cai Jie, Zhang Xin}

\author{
School of Law of Wuhan University, Wuhan 430072 Hubei
}

\begin{abstract}
For the misuse of technical investigation means is an infringement of the fundamental rights of citizens, the legal regulation of technical investigation should be perfected on application scope, approval procedure, relief mechanism and other aspects in order to solve the problem of abuse of the power of investigation. In this paper, the deficiencies of the technical investigation existing in practice are discussed and finally the basic strategies to perfect the legal regulation of technical investigation in China are described based on the analysis of characteristics and significance of legislative regulation of the technical investigation.
\end{abstract}

Keywords: Legal regulation, Technical investigation, Perfect measures, Conception

\section{INTRODUCTION}

With the development of the national economy and science and technology, forms and means of the crime are increasingly complicated and the application of investigation measures is also increasing. The technical investigation has the characteristics such as concealment, infringement and mandatory. In order to solve the crimes in investigation as soon as possible, officials often illegally use the technical investigation means so that the legal rights of the citizens are abused to a certain degree in the course of the administration of justice. The reason is that the national legal regulation of technical investigation is imperfection to some extent. For the improvement of the legal regulation of technical investigation of China, primarily the deficiencies of the technical investigation should be defined, the judicial procedure applicable to the technical investigation means shall be clearly defined and correspondingly a set of legitimate and rational usage specification of the technical investigation means should be developed in accordance with the current situation of the national judicature.

\section{Overview of Technical Investigation}

1. Definition of Technical Investigation. The technical investigation is kinds of investigation means implemented by use of modern science, technology and knowledge from a technical point of view, and is the secret investigation means carried out by the investigation executives using the technical equipment for the cases from the confidentiality perspective. According to the State Security Law and the interpretation of the legislators, the technical investigation mainly refers to various special investigation methods implemented by National Police Authorities and National Security Authorities to solve the crimes in investigation through mail trace checks, secretly obtaining evidence, secretly recording video, tracking, electronic monitoring, communication surveillance and other technical means.

\section{Characteristics of Technical Investigation.}

The technical investigation has the following characteristics: 1) Confidentiality, which mainly means that the investigation activities are only learnt by the executive personnel and all the investigation process and results are not learnt by other persons. 2) Infringement, the 
fundamental rights are infringed to some extent by reason of the investigation activities with various monitoring and surveillance adopted under the party concerned uninformed. 3) Mandatory, which mainly means that approval and consent of criminal suspects are unnecessary when the technical investigation means implemented. And 4) Hi-Tech, which mainly is that the technical investigation activities can be completed by means of various advanced technologies and devices, such as audio monitor, electronic monitor controller and so on.

\section{Significance of Legislative Regulation of Technical Investigation}

In order to ensure the uniformity of the national investigative power and avoid the misuse of the investigative power, the independent technical investigation branches should be created in China, "Checks and Balances" (Application Right, Approval Rights and Executive Rights) should be formed and the legislative regulation of technical investigation should be perfected to guarantee the legitimate rights of the citizens unviolated.

There are very important significances for the legislative regulation of technical investigation, specifically: 1) Ensure the effectiveness of technical investigation behavior. Effectively prevent the investigators tampering with intents or distorting the facts of the cases and abusing the investigation means. 2) Strengthen the human rights protection. Clearly define the reconsideration and litigation rights of the citizens, relief and protect the citizens when their privacy rights infringed, and offer the guarantee for the legitimate rights of the citizens. 3) Promote the building of a country under the rule of law. Establish the legislative regulation of technical investigation to restrict the technical investigation behavior under law and avoid the misuse of the investigative power.

\section{Deficiency of Law Regulation of Technical Investigation in China}

1. Unclearly Applicable Condition and Scope. It is difficult to conduct the effective management and the supervision is weak in the result of strong privacy and invasiveness in the technical investigation process. In Amendment to Criminal Law in China, the applicable scope related to the technical investigation means is stipulated as "other criminal cases harmful to social security", which is the legal terms with wider explanation space and doesn't clearly stipulate "what cases are applicable to the technical investigation means". Moreover, the relevant organs (Court and Investigation Organ) from different places, different levels or the same places have the inconsistent understanding and acquaintance on this terms. The unclear usage condition and scope of the technical investigation means, which creates the condition for users to abuse the technical investigation means. In addition, the investigation organs often believe their execution is in line with the law terms of "seriously endanger the social stability" and then start to adopt technical investigation means. Thus, the technical investigation means are often misused or used at random.

\section{Inexplicit Approval Procedure of Technical} Investigation. Although mail trace checks, tracking and monitoring, secretly recording video, communication surveillance and secretly taking photos are all the traditional technical investigation, the relevant judicial interpretations such as specific means, applicable objects, starting and approval procedure of the technical investigation are still unclear and the operability is poor. Take the amendments of Criminal Procedure Law in 
China as an example, the terms of "must pass the rigorous approval procedure" is stipulated in the justice for the approval of the technical investigation means, which seemingly is strict, but inexplicit, the approval procedure, approval charger and executive object are not stipulated clearly, which creates the condition for the investigation bodies in abusing the technical investigation means. In recent years, National Police Authorities and National Security Authorities have set up the technical investigation teams to handle the cases of misuse of authority and serious bribery and corruption. Considered from the current situation in China, all large organizations establish the technical investigation branches, which will result in the repeat construction of the technical investigation system, the repeat investment in the technical strength and equipment and even cause the competition and the resources grab with each other. In view of above situation, the proposal of adding technical investigation system by procuratorial organ is rejected in Amendment to Criminal Law, and the original regulations are still implemented.

3. Lack of Right Relief and Sanction Mechanism. If there are situations that the counterparts believe the investigation means adopted by the investigation authority infringe their legitimate rights, or challenge the investigation means used by the investigation authority, the judicial interpretations on how to implement the right relief is not issued yet. The right relief refers to the corresponding remedial measures are adopted by individuals or the relevant organs within the permissible scope of law to guarantee the obligee to receive appropriate indemnity and compensation and protect the legitimate rights of obligee when the substantive rights of the obligee are infringed. The right relief methods mainly include judicial relief, administrative justice relief and arbitration relief. At present, the clear stipulation of "relief procedure" is still lack in China's laws. The relief is a means of expression of the rights, and no relief no rights. Guaranteeing the legitimate relief rights of counterparts is an important weapon to ensure the legitimate investigation means. The implementation of the technical investigation means originally has high infringement and concealment, which means to disregard the assurance of human rights and violate the spirit of "Rule by Law" if not formulate the clear right relief procedure for the counterparts and not guarantee their basic rights from the law point of view. Therefore, "the investigation means impairing the legitimate rights of the citizens shall bear the corresponding legal responsibility and consequences" is clearly stipulated in China's Criminal Law and the relief procedure when the legitimate rights of the counterparts infringed is explicitly extablished.

\section{Settlement of Deficiency of Technical Investigation and Improvement of Law Regulation of Technical Investigation in China}

The technical investigation measure is the means to control and fight crimes, but which will seriously infringe the citizens' rights if there is slight mistake. Therefore, how to ensure normative, rational and strict to use technical investigation measures to prevent infringing the counterpart's rights is become the focus issue that must be solved. Although China has initially improved the technical investigation measures at present, the relevant legal regulations are overall with more principles, the corresponding applicable regulations are required to formulate and further define these legal regulation to coordinate the relationship between the protection of human rights and 
control of crimes in the actual use of the technical investigation authority.

\section{Definition of Basic Principles of Technical} Investigation. When investigation of cases, not all the criminal cases are applicable to the technical investigation measures and not any criminal suspects are the addressees applicable to the technical investigation means, and then the investigation authority shall determine whether apply the technical investigation means according to criminal character, roughly prison term, criminal severity and suspected accusation of the criminal suspects. The following principles should be abided by in using the technical investigation means: 1) Necessity principle, which mainly means to the technical investigation means used depending on the severity of criminal cases, and it is necessary to conduct the technical investigation if there is serious damage. 2) Correlation principle, which refers to implement the secret investigation means on the personnel closely related to the cases. 3) Rule-of-Law principle, namely adopt the secret investigation means according to laws and not violate the principle of judicial review. 4) Moderately Open principle, which mainly refers to the investigation means shall be moderately open to defender, criminal suspect and society. 5) Privacy Protection principle, namely protect the privacy rights of party concerned, prevent the reveal of relevant material and keep the evidence. 6) Relief principle, which means to endow party concerned the right to know, reconsideration right and action right to guarantee the basic rights of the party concerned.

\section{Delimitation of Subject Scope of Technical} Investigation. The technical investigation subjects with the technical power shall be delimited clearly in new Criminal Procedure Law, including The People's Procuratorate,
Public Security Authority and National Security Authority. For the executive bodies of technical investigation, not only Public Security Authorities shall be delimited, but also the criminal investigation pressure of Police Authorities should be relieved and the technical investigation efficiency shall be improved according to the investigation criminal features and the actual situation in China and following the rule of law of "implementation depending on who applying".

3. Definition of Category of Technical Investigation. The concept of technical investigation shall be delimited clearly in new Criminal Procedure Law, and the category of technical investigation shall be further defined in the form of a list based on the confidentiality characteristic of the technical investigation. Due to the legal regulation in China still in the underdeveloped stage at present, the technical investigators will misinterpret the technical investigation measures and misuse the technical investigation power if the detail rules and regulations of technical investigation are not formulated. Therefore, the technical investigation category shall be explicitly stipulated in Criminal Procedure Law, namely The People's Procuratorate, Public Security Authority and National Security Authority shall adopt the technical means, such as secret arrest and capture, tracking, mail checker, electronic surveillance, secret identification, secret video recording, electronic monitoring, waiting for monitor, and so on.

\section{Definition of Applicable Scope of Technical} Investigation. The specific applicable scope of technical investigation means, such as secret video recording, sound recording, photos taking, communication monitoring and secret tracking, shall cover drug smuggling cases, terrorist attacks, organization crime cases, serious 
corruption cases, major cases harmful to national interest, emergency cases, and other criminal cases with more than 3 years in prison. The technical investigation means shall be implemented for the criminal cases harmful to the national security because these cases have serious impacts on national sovereignty, regime solidity and territorial integrity. There are the characteristics of complexity, serious hazards, many of persons involved for the organization crime cases, and there will be low possibility for the criminal investigation and it is difficult to restore the case facts if the investigation means including secret photograph, communication eavesdropping and tracking are not adopted. The criminal cases with more than 3 years in prison, which generally are the crime cases seriously harmful to the social security, can be performed by the technical investigation means to limit the rights of minority criminal suspects and protect the rights of majority persons. The cases with less than 3 years in prison, which relatively have less hazards, are not applicable to the technical investigation measures, and shall be on file for investigation according to the conventional method. If adopt the conventional investigation means for the emergency cases, it is easy to lose the optimal opportunity to solve a case. Thus, the secret investigation means can be applied to shorten the time to solve a case and improve litigation efficiency. The criminal suspects are not the sole objects applicable to the technical investigation measures, and the technical investigation means can be implemented if there is direct relevance between other personnel and cases. But it should be noted that the other third parties don't include the lawyer of suspects. In addition, it is required to clearly point out that the conventional investigation measures shall be firstly chosen for above crime cases in the process of investigation, and then the technical investigation means shall be used when unable to successfully solve a case with the conventional investigation means.

\section{Emphasis of Evidence Effectiveness of} Technical Investigation. The material collected by the investigation means can be used as the evidences and has the evidence effectiveness, which has definitely stipulated and emphasized in Criminal Procedure Law and even fundamentally changes the practical problems that the material collected by the technical investigation converted into the evidences in the form of writing records in the past judicial practice. However, it should be defined that not all the material acquiring by the technical investigation has the evidence effectiveness. Due to the technical investigation itself owning the characteristics of mandatory, infringement and confidentiality, the judicial department shall establish the complete regulations of technical investigation to eliminate the illegal evidences, which means that the evidences acquired by the law-breaking have no legal effectiveness, with the except of the serious crimes harmful to social security and national interests. In addition, the applicable scope of material collected by the technical investigation has been explicitly stipulated in new "Criminal Procedure Law", which shall not be used for other aspects except for criminal investigation, litigation and trial, and limit the evidence effectiveness scope of material acquired by the technical investigation to some extent. For the technical investigation having the characteristics of mandatory and infringement, the evidences obtained by the technical investigation can only be used for the criminal proceedings of one case. If the material related to the case can prove other major crimes (based on the criminal suspects with more than 3 years in prison.), the evidences obtained by 
the technical investigation and used for the case can be applied to other cases after the strict approval.

\section{Strict Approval Procedure of Technical} Investigation. In order to avoid the misuse of investigation power of the investigation authorities and the infringement of the fundamental rights of citizens, the current legal status and the investigation system in China should be considered comprehensively to establish the strict approval procedure of technical investigation means and appoint the procuratorate to approve. From the point of criminal procedure law, the procuratorate is belong to the legal supervision authority, and the feasibility is enormous if the approval rights of the technical investigation means are endowed to the procuratorate. In view of this situation, the operational laws and regulations of approval power should be formulated, the review process, monitor process and approval recording procedure of the technical investigation rights are should be perfected, and the relief mechanism implemented after the inappropriate application of the investigation procedure shall be improved. For the feasibility that the approval power handed over to the procuratorate, the author thinks we should pay attention to 1 ) the procuratorate shall apply the approval letter issued to the investigation and supervision department when the technical investigation means is needed if the approval power is handed over to the procuratorate. 2) the procuratorate shall make a written review on the technical investigation application by laws and take arbitration on the reasonable application, without an additional special investigation group when using approval rights. 3) after the approval of the procuratorate, the written consent shall be issued, which specifically includes the approval authority's names, reason, facts, the executive authority's names and the staff's names, the identity and name of party concerned, the technical investigation means and applicable scope, the investigation sites, purpose, etc.

7. Establishment of Infringement Relief Mechanism of Technical Investigation. The technical investigation should be at the cost of "infringement" to some extent. In order to guarantee the foundational rights of citizens and reduce the cost of technical investigation, the technical investigation procedure should be rationally designed to make the privacy rights of citizens obtained when the infringement of rights in accordance with the corresponding infringement relief rules. The specific relief measures are 1) to endow party concerned with the right to know. On the one hand, to guarantee the rights of party concerned to avoid the rights infringed by the investigation authority, on the other hand, to prevent the investigator tampering the original intention and distorting the facts of the cases, and make good preparation through checking and determining the trueness after informing party concerned. 2) to endow the review right to party concerned. The party concerned can put forward the reconsideration to the relevant authority when the protest on the investigation means of investigation authority is proposed. If the investigation means adopted by the investigation authority really is illegal or violates the applicable principle, the technical investigation means should be stopped immediately and make compensation to the party concerned. 3) to prosecute. Party concerned can take a legal action to the investigation executives or the investigation authorities for guaranteeing the individual rights when the legitimate rights of the party 
concerned encounter the infringement of illegal technical investigation means.

\section{Conclusions:}

There is no clear definition for the applicable objects of the technical investigation cases in the current criminal law in China, which indicates that the technical investigation means has the applicable objects not only including the criminal suspects, but also the friends and the family members of the suspects, and the investigation authority completely can subjectively judge if the technical investigation means used or not. In order to solve the problem of the misuse of the technical investigation, the basic principle of technical investigation should be strictly followed, the applicable object and scope of the technical investigation means shall be explicitly defined, and the legal consequences should be emphasized to bear if the misuse of the investigation power in order to promote the use of legality, rationality and standardization of the technical investigation means and fully protect the rights of party concerned.

\section{References}

[1] Zeng Jun. Extraterritorial Implications of Improvement of Technical Investigation System in China [J]. The People's Procuratorate, 2013(01):70-73
[2] Ai Ming. Defects and Improvement of Legal Regulation of Technical Investigation Measures in China [J]. Journal of Gansu Political Science and Law Institute, 2013, 06(13):7-14

[3] $\mathrm{Xu}$ Zhi. Defects and Improvement of Technical Investigation Legislation in New Criminal Procedure Law in China $[\mathrm{J}]$. Social Scientist, 2014, 04(12):92-97

[4] Dong Lintao. Analysis on Several Issues of Legal Interpretation of "Technical Investigation" - In the Legal Hermeneutic View $[\mathrm{J}]$. Journal of Chongqing Technology and Business University (Social Science Edition), 2014, 31(04):114-119

[5] Guo Yongliang. Study on Legal Regulation of Technical Investigation in China [J].

Hubei Social Sciences, 2010(03):158-161

[6] Zhang Changyong. Procedure of Investigation and Protection of Human Rights Reformation and Improvement of Investigation Procedure in China [M]. Beijing: China Legal Publishing House, 2009

[7] $\mathrm{Hu}$ Ming. Technical Investigation: Fuzzy Authorization or Strict Regulation - Center to the Article 263 of Rules of Criminal Rules of the People's Procuratorate (Trial) [J]. Tsinghua Law Review, 2013, 06(14):36-45 